\title{
PELATIHAN PENYUSUNAN PROGRAM PEMBELAJARAN PENDIDIKAN KARAKTER ANAK USIA DINI PADA GURU TK
}

\author{
Mazia Amalia dan Wisjnu Martani \\ Tim Program Inklusi, SMA Muhamadiyah Cilegon, Jl. Perintis No 03 Link. Lokal, \\ Kota Cilegon dan Fakultas Psikologi, Universitas Gadjah Mada \\ liamazia@gmail.com dan wisjnu_m@ugm.ac.id
}

\begin{abstract}
The key of the successful character education program are teachers, school employees and all the school environment because the focus of the character education is the school culture especially kindergarten children who are at the early stage of education. The accomplishment of character education at school is impeded the teachers who are have not understood on how to integrate it into school subjects. The purpose of this research is to test the training of My Plan My Success in improving kindergarten teacher's ability toward the arrangement of the learning program for character education in young children. This research involved 36 teachers which were divided into experimental (18 teachers) and control (18 teachers) group, using experimental design: untreated control group design with dependent pretest and posttes samples using switching replication. The result of the data analysis that uses analysis data methode namely mixed anova shows there is different ability in the arrangement of learning program for character education in young children significantly ( $F=8,576$; $\mathrm{p}<0,01)$. The training gives the effective contribution to experimental group as much as $61,7 \%$. The ability of the,arrangement of learning program for character education in young children in the experimental group is improving $(\mathrm{MD}=-6,824 ; \mathrm{p}<0,01)$, after getting intervention. As well as the control group, after getting intervention, there ability is getting improve $(\mathrm{MD}=-$ $5,765 ; \mathrm{p}<0,00)$.
\end{abstract}

Keywords : learning program for character education in young children, preschool teacher training. 


\begin{abstract}
Abstrak
Kunci dari suksesnya program pendidikan karakter adalah guru, karyawan sekolah dan seluruh lingkungan sekolah lainnya karena pendidikan karakter fokusnya adalah budaya sekolah khususnya untuk anak TK yang masih mengawali dunia pendidikannya. Pelaksanaan pendidikan karakter di sekolah masih terkendala guru yang belum memahami bagaimana mengintegrasikannya dalam materi pelajaran sekolah. Tujuan dari penelitian ini adalah menguji pelatihan My Plan My Success dalam meningkatkan penguasaan guru TK terhadap penyusunan program pembelajaran pendidikan karakter anak usia dini. Penelitian ini melibatkan guru TK sebanyak 36 orang yang dibagi menjadi kelompok eksperimen (18 orang) dan kelompok kontrol (18 orang), menggunakan desain eksperimen untreated control group design with dependent pretest and posttes samples using switching replication. Hasil analisis data yang menggunakan metode analisis data mixed anova menunjukkan ada perbedaan penguasaan penyusunan program pembelajaran pendidikan karakter AUD secara signifikan $(F=8,576$; $p<0,01)$ pada kelompok eksperimen setelah mendapatkan perlakuan. Sumbangan efektif pelatihan pada kelompok eksperimen sebesar 61,7\%. Pada kelompok eksperimen, penguasaan penyusunan program pembelajaran pendidikan karakter AUD mengalami peningkatan ( $\mathrm{MD}=-6,824 ; \mathrm{p}<0,01$ ). Pada kelompok kontrol, setelah diberikan perlakuan, penguasaan subjek juga mengalami peningkatan $(\mathrm{p}<0,00)$.
\end{abstract}

Kata kunci : pelatihan, program pembelajaran pendidikan karakter AUD, guru TK.

\title{
Pendahuluan
}

Indonesia menduduki peringkat keempat dunia dari sisi jumlah guru dan sekolah, meskipun demikian Indonesia belum bisa bersaing dari sisi kualitas pendidikan. Penyebab utama hal tersebut adalah masih rendahnya mutu guru. (Nugraha, 2009). Para guru di Indonesia masih kurang bisa memerankan fungsinya, salah satu penyebabnya karena pemerintah masih kurang memperhatikan mereka, khususnya dalam upaya meningkatkan profesionalismenya (Supriyoko, 2002).

Peran guru bukan sekadar mentransfer pelajaran kepada peserta didik. Tapi lebih dari itu guru bertanggungjawab membentuk karakter peserta didik sehingga 
menjadi generasi yang cerdas, saleh, dan terampil dalam menjalani kehidupannya. Menyadari hal ini, pemerintah mulai tahun ajaran 2011/2012 menjadikan pendidikan berbasis karakter sebagai gerakan nasional mulai dari Pendidikan Anak Usia Dini (PAUD) sampai Perguruan Tinggi termasuk pendidikan nonformal dan informal (Nurchaili, 2011).

Wakil Menteri Pendidikan dan Kebudayaan Musliar Kasim menyatakan pelaksanaan pendidikan karakter di sekolah masih terkendala guru yang belum memahami bagaimana mengintegrasikannya dalam materi pelajaran sekolah (Antara News, 2012). Menurut Handoyo (2012) implementasi pendidikan karakter di sekolah masih menghadapi banyak kendala, diantaranya terletak pada sosok guru sebagai aktor utama. Guru belum memahami konsep pendidikan karakter secara menyeluruh. Guru juga belum memiliki kompetensi yang memadai untuk mengintegrasikan nilainilai karakter pada materi dan kegiatan pembelajaran di sekolah. Kunci dari suksesnya program pendidikan karakter terletak pada guru, kemudian karyawan sekolah dan seluruh lingkungan sekolah lainnya karena pendidikan karakter fokusnya adalah budaya sekolah khususnya untuk anak TK yang masihmengawali dunia pendidikannya. Setelah itu peranan orangtua dan masyarakat sebagai penunjang dan penguat karakter (Saptono, 2012).

Dari studi awal yang dilakukan terhadap 28 guru Taman Kanak-kanak di kecamatan M kota Yogyakarta ditemukan bahwa para guru TK belum pernah mendapatkan pelatihan atau kegiatan yang ditujukan untuk menyusun program pembelajaran pendidikan karakter anak usia dini baik dari pemerintah dalam hal ini dinas pendidikan maupun dari institusi lain. Menurut pengawas TK di kecamatan N dan M, masih di kota Yogyakarta, sosialisasi mengenai pendidikan karakter sudah pernah dilakukan dalam tataran pengenalan dan pengetahuan materi.

Meskipun sudah ada upaya untuk meningkatkan pemahaman guru terhadap materi pendidikan karakter anak usia dini namun baru sebatas pada tataran pengenalan dan sosialisasi. Sebagai ujung tombak pendidikan, guru dituntut memiliki kompetensi yang memadai sebagaimana telah diatur dalam Peraturan Pemerintah Republik Indonesia Nomor 74 tahun 2008 tentang Guru. Salah satu komponen kompetensi guru adalah kompetensi pedagogik dimana disebutkan bahwa guru harus mampu melakukan perancangan pembelajaran, sehingga diperlukan satu upaya terstruktur agar guru mampu menyusun perancangan program pembelajaran pendidikan karakter untuk anak usia dini.

Menurut Noe, Hollenbeck, Gerhart dan Wright (2003) pelatihan merupakan suatu usaha yang terencana untuk memfasilitasi pembelajaran tentang pekerjaan yang 
berkaitan dengan pengetahuan, keahlian dan perilaku oleh para pegawai. Pelatihan yang dimaksud adalah pelatihan formal yang direncanakan secara matang dan mempunyai suatu format pelatihan yang terstruktur.

Berdasar pada paparan diatas maka upaya terstruktur yang hendak dilakukan agar guru TK mampu menyusun program pembelajaran pendidikan karakter anak usia dini adalah melalui pelatihan. Agar pelatihan menjadi efektif maka di dalam pelatihan harus mencakup suatu pembelajaraan atas pengalaman-pengalaman, pelatihan harus menjadi kegiatan keorganisasian yang direncanakan dan dirancang didalam menanggapi kebutuhan-kebutuhan yang teridentifikasi (Bernardin \& Russell, 1998).

Menurut teori humanistik, tujuan belajar adalah untuk memanusiakan manusia. Teori ini memandang belajar sebagai sebuah proses yang terjadi dalam individu yang melibatkan seluruh bagian atau domain yang ada yang meliputi domain kognitif, afektif dan psikomotorik. Untuk itu, metode pembelajaran humanistik mengarah pada upaya untuk mengasah nilai-nilai kemanusiaan pembelajar. Individu/siswa berperan sebagai pelaku utama (student center) yang memaknai proses pengalaman belajarnya sendiri (Rogers, 1987).

Belajar melalui pengalaman merupakan sebuah model holistik dari proses pembelajaran di mana manusia belajar, tumbuh dan berkembang. Penyebutan istilah experiential learning dilakukan untuk menekankan bahwa experience (pengalaman) berperan penting dalam proses pembelajaran dan membedakannya dari teori pembelajaran lainnya seperti teori pembelajaran kognitif ataupun behaviorisme (Kolb, 1984).

Experiential learning menurut Kolb, Boyatzis dan Maeremelis (1999) adalah suatu metode proses belajar mengajar yang mengaktifkan pembelajar untuk membangun pengetahuan dan keterampilan serta nilai-nilai juga sikap melalui pengalamannya secara langsung. Oleh karena itu, metode ini akan bermakna pada saat pembelajar berperan serta dalam melakukan kegiatan pembelajaran.

Tahap-tahap pelaksanaan model belajar experiential learning dimulai dengan melakukan (do), merefleksikan (reflect) dan kemudian menerapkan (apply). Jika dielaborasi lagi maka akan terdiri dari lima langkah, yaitu dimulai dari proses mengalami (experience), berbagi (share), menganalisis pengalaman tersebut (proccess), mengaitkan pengalaman dengan kejadian nyata (generalize), dan menerapkan halhal yang telah dipelajari pada situasi yang sama atau berbeda (apply). Demikian seterusnya, kembali pada langkah pertama. Siklus ini tidak pernah berhenti (Pfeiffer \& Ballew, 1988).

Berdasarkan paparan diatas maka penelitian ini akan menggunakan pelatihan 
dengan metode experiential learning dimana para peserta pelatihan nantinya akan menghasilkan suatu program konkret yang langsung dapat diaplikasikan di sekolah.

Metode pelatihan terbukti efektif untuk meningkatkan pemahaman, penguasaan dan ketrampilan guru pada suatu materi pembelajaran (When Chong, 2010; Wati, 2012; Pistorio, 2009; Sariçoban \& Bariskan, 2005). Penyampaian materi program pembelajaran melalui metode pelatihan juga mampu meningkatkan kepercayaan diri guru serta motivasi sebagai guru (Wati, 2012).

Pelatihan dalam penelitian ini hendak memberikan materi penyusunan program pembelajaran pendidikan karakter AUD. Rencana program pembelajaran adalah peta jalan yang akan menjadi pedoman bagi guru dari apa yang diperlukan siswa untuk belajar dan bagaimana itu akan dilakukan secara efektif selama waktu kelas (Milkova, 2011). Penyusunan program pembelajaran sebagai materi pelatihan dalam penelitian ini menggunakan pendekatan Model Kemp. Model ini adalah model yang berorientasi sistem yaitu model desain pembelajaran untuk menghasilkan suatu sistem pembelajaran yang cakupannya luas, seperti desain sistem suatu pelatihan, kurikulum sekolah, dll. (Muliartha, 2011). Dalam model Kemp (Akbulut, 2007; Irastorza, Begin \& Fabry, 2008; Morrison, Ross \& Kemp, 2004; Park \& Confessore, 2007) terdapat beberapa langkah dalam penyusunan sebuah bahan ajar, yaitu

a. Menentukan tujuan dan daftar topik, menetapkan tujuan umum untuk pembelajaran tiap topiknya;

b. Menganalisis karakteristik pelajar, untuk siapa pembelajaran tersebut didesain;

c. Menetapkan tujuan pembelajaran khusus yang ingin dicapai dengan syarat dampaknya dapat dijadikan tolak ukur perilaku pelajar;

d. Menentukan isi materi pelajaran yang dapat mendukung tiap tujuan;

e. Pengembangan prapenilaian/ penilaian awal untuk menentukan latar belakang pelajar dan pemberian level pengetahuan terhadap suatu topik;

f. Memilih aktivitas pembelajaran dan sumber pembelajaran yang menyenangkan atau menentukan strategi belajar-mengajar, jadi siswa-siswa akan mudah menyelesaikan tujuan yang diharapkan;

g. Mengkoordinasi dukungan pelayanan atau sarana penunjang yang meliputi personalia, fasilitas-fasilitas, perlengkapan, dan jadwal untuk melaksanakan rencana pembelajaran;

h. Mengevaluasi pembelajaran siswa dengan syarat mereka menyelesaikan pembelajaran serta melihat kesalahan-kesalahan dan peninjauan kembali beberapa fase dari perencanaan yang membutuhkan perbaikan yang terus menerus, evaluasi yang dilakukan berupa evaluasi formatif dan evaluasi sumatif.

Guru harus memahami terlebih dahulu prinsip-prinsip pembelajaran anak usia dini dalam mengembangkan rencana program pembelajaran pendidikan karakter 
AUD. Menurut UU RI No 20 tahun 2003 yang termasuk dalam anak usia dini adalah anak dengan rentang usia 0-6 tahun. Tahap awal kehidupan ini disebut juga masa keemasan atau golden age karena ada seratus miliar sel otak yang siap distimulasi dan siap menyerap pengetahuan jauh lebih kuat dibandingkan orang dewasa. Sel otak akan dapat berkembang jika distimulasi dengan tepat.

Karakter adalah seperangkat kompleks karakteristik psikologis yang memungkinkan seorang individu untuk bertindak sebagai agen moral. Hal ini bersifat psikologis dan terkait dengan fungsi moral (Berkowitz, 1997; Peters, 2009, Rivers, 2004;). Lickona (1992) memberikan suatu cara berpikir tentang karakter bagi pendidikan nilai : karakter terdiri dari nilai operatif atau nilai dalam tindakan. Karakter yang terasa demikian memiliki tiga bagian yang saling berhubungan, yaitu: pengetahuan moral, perasaan moral, dan perilaku moral. Karakter yang baik terdiri dari mengetahui hal yang baik, menginginkan hal yang baik, dan melakukan hal yang baik - kebiasaan dalam cara berpikir, kebiasaan dalam hati, dan kebiasaan dalam tindakan.

Dalam pendidikan karakter anak usia dini, Miller dan Pedro (2006 dalam Singer, 2010) didukung oleh Schultz, Selman dan LaRusso (2003) meyakini bahwa dunia di mana anak-anak menemukan diri mereka hari ini, memahami dan menghargai dengan siapa mereka bersekolah, belajar dan bermain, membuat mereka hidup jauh lebih kaya dan memiliki pengalaman belajar, memperluas cakrawala, dan memecah hambatan tradisional.

Pada buku Pedoman Pendidikan Karakter Pada Pendidikan Anak Usia Dini Yang Dikeluarkan oleh Direktorat Pembinaan Pendidikan Anak Usia Dini, Direktorat Jenderal Pendidikan Anak Usia Dini, Nonformal, Dan Informal, Kementerian Pendidikan Nasional tahun 2012, karakter didefinisikan sebagai tabiat atau kebiasaan untuk melakukan hal yang baik. Sedangkan nilai-nilai karakter adalah sikap dan perilaku yang didasarkan pada norma dan nilai yang berlaku di masyarakat, yang mencakup aspek spiritual, aspek personal/kepribadian, aspek sosial, dan aspek lingkungan. Oleh karena itu pendidikan karakter didefinisikan sebagai upaya penanaman nilai-nilai karakter kepada anak didik yang meliputi pengetahuan, kesadaran atau kemauan, dan tindakan untuk melaksanakan nilai-nilai kebaikan dan kebajikan, kepada Tuhan YME, diri sendiri, sesama, lingkungan maupun kebangsaan agar menjadi manusia yang berakhlak.

Perencanaan pendidikan karakter pada anak usia dini dikembangkan dengan memperhatikan hal-hal berikut (Buku Pedoman Pendidikan Karakter Pada Pendidikan Anak Usia Dini, 2012) : 
1. Mengenal dan memahami anak seutuhnya sesuai dengan tahapan perkembangan dan karakteristiknya, seperti anak sebagai peneliti ulung, aktif gerak, pantang menyerah, maju tak pernah putus asa, terbuka, bersahabat, dan tak membedakan.

2. Nilai-nilai pendidikan karakter diterapkan menyatu dengan kegiatan inti proses belajar mengajar yang dilakukan dengan cara:

a. Memilih nilai-nilai karakter yang sesuai dengan tema dan judul kegiatan pembelajaran.

b. Menentukan indikator perkembangan nilai-nilai karakter, sesuai dengan tahap perkembangan anak

c. Menentukan jenis dan tahapan kegiatan yang akan dilaksanakan.

Tujuan dari penelitian ini adalah untuk menguji pelatihan My Plan My Success dalam meningkatkan penguasaan guru TK terhadap penyusunan program pembelajaran pendidikan karakter anak usia dini. Hipotesis dalam penelitian ini adalah pelatihan My Plan My Success mampu meningkatkan penguasaan guru TK dalam menyusun program pembelajaran pendidikan karakter anak usia dini.

\section{Metode Penelitian}

Subjek dalam penelitian ini adalah guru TK yang memenuhi kriteria sebagai berikut: berlatar belakang pendidikan S1 dan memiliki posisi sebagai wali kelas. Penguasaan guru TK dalam menyusun program pembelajaran pendidikan karakter AUD diukur dengan Skala Pengetahuan Penyusunan Program Pembelajaran Pendidikan Karakter AUD yang dibuat berdasarkan langkah-langkah dalam penyusunan sebuah bahan ajar Model Kemp sebagai aspeknya. Penelitian ini menggunakan metode eksperimen kuasi dengan kelompok kontrol dan kelompok eksperimen. Desain eksperimen yang digunakan adalah Untreated control group design with dependent pretest and posttes samples using switching replication. Penggunaan desain eksperimen dalam penelitian ini dapat digambarkan sebagai berikut

\begin{tabular}{|lllllll|}
\hline KE & NR & O1 & X & O2 & & O3 \\
KK & NR & O1 & & O2 & X & O3 \\
\hline
\end{tabular}

Keterangan :

KE : Kelompok eksperimen $\quad \mathrm{KK} \quad$ : Kelompok kontrol

NR : Non Randomized $\quad$ X : Perlakuan

$\mathrm{O} 1$ : Pretest O2 : Posttest

O3 : Posttes kedua untuk KE dan posttest kedua untuk KK setelah perlakuan 
Penelitian ini menggunakan intervensi yang berbentuk pelatihan dengan metode experiential learning. Pelatihan dalam penelitian ini hendak memberikan materi langah-langkah dalam menyusun program pembelajaran pendidikan karakter AUD berdasarkan desain pembelajaran Model Kemp. Langkah-langkah penyusunan program pembelajaran Model Kemp adalah :

1. Menentukan tujuan umum untuk pembelajaran.

2. Menganalisis karakteristik pelajar.

3. Menetapkan tujuan pembelajaran yang ingin dicapai dengan syarat dampaknya dapat dijadikan tolak ukur perilaku pelajar.

4. Menentukan isi materi pelajaran yang dapat mendukung tiap tujuan.

5. Pengembangan prapenilaian/ penilaian awal untuk menentukan latar belakang pelajar dan pemberian level pengetahuan terhadap suatu topik.

6. Memilih aktivitas pembelajaran dan sumber pembelajaran yang menyenangkan atau menentukan strategi belajar-mengajar.

7. Mengkoordinasi dukungan pelayanan atau sarana penunjang untuk melaksanakan rencana pembelajaran.

8. Menentukan alat evaluasi pembelajaran siswa.

Materi pelatihan dalam penelitian ini hendak dibawakan oleh trainer dengan kriteria sebagai berikut : memiliki latar belakang ilmu Sarjana Psikologi, berpengalaman berinteraksi dengan guru TK selama kurang lebih satu tahun baik terlibat langsung dalam kegiatan pembelajaran di TK maupun sebagai konsultan pembelajaran TK, berpengalaman menjadi narasumber atau berpengalaman memberikan materi dihadapan guru TK baik dalam bentuk ceramah, diskusi, pelatihan, dll.

Subjek penelitian berasal dari 18 TK yang ada di kecamatan M, Kota Yogyakarta. Masing-masing TK mengirimkan dua orang guru. Penelitian ini melibatkan 36 orang guru TK yang dibagi menjadi 18 orang sebagai kelompok eksperimen dan 18 orang sebagai kelompok kontrol. Menentukan kelompok eksperiman dan kelompok kontrol dengan cara mengundi 18 TK yang ada menjadi dua kelompok sehingga didapatkan sembilan TK sebagai kelompok kontrol dan sembilan TK sebagai kelompok eksperiman. Melaksanakan pre-test pada kelompok kontrol dan mengisi informed consent sekaligus menjelaskan pada kelompok kontrol bahwa intervensi pada mereka akan diberikan pada gelombang kedua.

Pelatihan My Plan My Success dilaksanakan dalam tiga kali pertemuan, setiap pertemuan kurang lebih membutuhkan waktu 240 menit. Pertemuan pertama guru menentukan tujuan umum dalam pembelajaran dan belajar menganalisis karateristik siswa, pertemuan kedua guru belajar menetapkan tujuan pembelajaran khusus dan menentukan isi materi pelajaran yang dapat mendukung tujuan pembelajaran serta 
pengembangan penilaian awal terhadap kondisi siswa, pertemuan ke tiga guru belajar memilih aktivitas pembelajaran dan sumber pembelajaran yang menyenangkan atau menentukan strategi belajar mengajar (insert pendidikan karakter), mengkoordinasi dukungan pelayanan atau sarana penunjang, kemudian membuat evaluasi pembelajaran siswa dan terakhir membuat rangkuman keseluruhan materi.

Penguasaan guru TK dalam menyusun program pembelajaran pendidikan karakter AUD diukur dengan Skala Pengetahuan Penyusunan Program Pembelajaran Pendidikan Karakter AUD yang dibuat berdasarkan langkahlangkah dalam penyusunan sebuah bahan ajar Model Kemp sebagai aspeknya. Skala Pengetahuan Penyusunan Program Pembelajaran Pendidikan Karakter AUD berbentuk pernyataan dan berisi lima pilihan dari Sangat sesuai (SS), Sesuai(S), Netral (N), Tidak Sesuai (TS) dan Sangat Tidak Sesuai (STS). Contoh Skala Pengetahuan Penyusunan Program Pembelajaran Pendidikan Karakter AUD seperti: Saya memahami dan bisa merumuskan tujuan pembelajaran pendidikan karakter untuk anak TK, Sebelum memulai kegiatan pembelajaran di awal semester saya mencoba mengenali kondisi siswa di kelas yang hendak saya pegang, Mengetahui kondisi pengetahuan siswa mengenai nilai-nilai moral bermanfaat bagi evaluasi akhir, Saya memiliki bahan-bahan rujukan yang cukup lengkap (buku teks, buku panduan, dll) mengenai materi pembelajaran pendidikan karakter, dll.

Pelatihan My Plan My Succes juga diberikan kepada kelompok kontrol, setelah selesai diberikan pada kelompok eksperimen yang kemudian dilanjutkan dengan post-tes kedua pada kelompok kontrol dan tahap selanjutnya melakukan post-test kedua pada kelompok eksperimen.

Data yang akan diperoleh dalam penelitian ini dianalisis dengan menggunakan metode analisis data mixed anova.

\section{Hasil dan Pembahasan}

Skala Pengetahuan Penyusunan Program Pembelajaran terdiri dari 38 aitem, setelah dilakukan analisis terhadap data yang diperoleh didapatkan 27 aitem sahih dan 11 aitem gugur. Indeks daya diskriminasi aitem berkisar antara 0,251 - 0,687. Uji keandalan alat ukur pada 27 aitem sahih menghasilkan koefisien reliabilitas Alpha sebesar 0,842.

Uji normalitas dilakukan terlebih dahulu sebelum dilakukan analisis data mixed anova. Analisis data menggunakan metode parametrik. Hasil uji normalitas menggunakan metode Kolmogorov-Smirnov menunjukkan bahwa data pretest, post- 
test 1 dan post-test 2 berada dalam distribusi normal dengan nilai signifikansi masingmasing sebesar 0,$842 ; 0,848$ dan 0,783. Suatu data dikatakan berdistribusi normal apabila memiliki nilai signifikansi $>0,05$. Oleh karena data yang diperoleh dalam penelitian ini terbukti berdistribusi normal maka metode statistik parametrik dapat digunakan untuk analisis data.

Menurut Ramsey (dalam Widhiarso, 2011) nilai Box’s M yang menunjukkan data tidak homogen dapat diabaikan karena dua hal. Pertama, studi yang dilakukan oleh Norton menunjukkan bahwa homogenitas data pada eksperimen dapat diabaikan. Kedua, anova -metode analisis data yang digunakan dalam peneltian ini-termasuk uji yang robust (kuat) terhadap gangguan heterogenitas data, jika ukuran sampel kedua kelompok tidak terlalu besar yaitu selisihnya antara 7 hingga 15 subjek.

Setelah uji normalitas terpenuhi dan uji homogenitas dapat diabaikan maka dilakukan uji hipotesis dengan menggunakan metode analisis data mixed anova yang diolah dengan SPSS Statistics 17.0.

Tabel 1. Interaksi Time*Group

Tests of Within-Subjects Effects

Measure:MEASURE_1

\begin{tabular}{llcccccc}
\hline & Source & $\begin{array}{c}\text { Type III } \\
\text { Sum of } \\
\text { Squares }\end{array}$ & df & \multicolumn{1}{c}{$\begin{array}{c}\text { Mean } \\
\text { Square }\end{array}$} & F & Sig. $\begin{array}{c}\text { Partial Eta } \\
\text { Squared }\end{array}$ \\
\hline time * $_{\text {Group }}$ & Sphericity Assumed & 178.902 & 2 & 89.451 & 8.576 & .001 & .211 \\
& Greenhouse-Geisser & 178.902 & 1.692 & 105.708 & 8.576 & .001 & .211 \\
& Huynh-Feldt & 178.902 & 1.833 & 97.621 & 8.576 & .001 & .211 \\
& Lower-bound & 178.902 & 1.000 & 178.902 & 8.576 & .006 & .211 \\
\hline
\end{tabular}

Dari hasil analisis data diperoleh nilai F sebesar 8,576 ( $<<0,01)$ pada bagian time*group. Hal ini menunjukkan bahwa terdapat interaksi antara time atau waktu (pre-post1-post2) dan group (kontrol-eksperimen). Interaksi menunjukkan bahwa ada perbedaan secara signifikan pada perubahan skor pre-tes menuju post-tes pada kedua kelompok (kontrol-eksperimen). Hasil ini memberikan arti bahwa hipotesis penelitian yang berbunyi pelatihan My Plan My Success mampu meningkatkan penguasaan guru TK dalam menyusun program pembelajaran pendidikan karakter AUD diterima. 
Tabel 2. Interaksi Masing-masing Time

\section{Pairwise Comparisons}

Measure:MEASURE_1

\begin{tabular}{|c|c|c|c|c|c|c|c|}
\hline \multirow{2}{*}{ Group } & \multirow{2}{*}{$\begin{array}{l}\text { (I) } \\
\text { time }\end{array}$} & \multirow{2}{*}{$\begin{array}{l}(\mathrm{J}) \\
\text { time }\end{array}$} & \multirow{2}{*}{$\begin{array}{c}\text { Mean } \\
\text { Difference } \\
(\mathrm{I}-\mathrm{J})\end{array}$} & \multirow{2}{*}{ Std. Error } & \multirow[t]{2}{*}{ Sig. ${ }^{a}$} & \multicolumn{2}{|c|}{$\begin{array}{c}\text { 95\% Confidence Interval for } \\
\text { Difference }^{\mathrm{a}}\end{array}$} \\
\hline & & & & & & Lower Bound & Upper Bound \\
\hline \multirow[t]{6}{*}{1} & 1 & 2 & -.353 & 1.017 & .731 & -2.424 & 1.718 \\
\hline & & 3 & $-5.765^{*}$ & 1.321 & .000 & -8.455 & -3.074 \\
\hline & 2 & 1 & .353 & 1.017 & .731 & -1.718 & 2.424 \\
\hline & & 3 & $-5.412^{*}$ & .950 & .000 & -7.347 & -3.476 \\
\hline & 3 & 1 & $5.765^{*}$ & 1.321 & .000 & 3.074 & 8.455 \\
\hline & & 2 & $5.412^{*}$ & .950 & .000 & 3.476 & 7.347 \\
\hline \multirow[t]{6}{*}{2} & 1 & 2 & $-6.824^{*}$ & 1.017 & .000 & -8.895 & -4.753 \\
\hline & & 3 & $-8.588^{*}$ & 1.321 & .000 & -11.279 & -5.898 \\
\hline & 2 & 1 & $6.824^{*}$ & 1.017 & .000 & 4.753 & 8.895 \\
\hline & & 3 & -1.765 & .950 & .073 & -3.700 & .171 \\
\hline & 3 & 1 & $8.588^{*}$ & 1.321 & .000 & 5.898 & 11.279 \\
\hline & & 2 & 1.765 & .950 & .073 & -.171 & 3.700 \\
\hline
\end{tabular}

Based on estimated marginal means

a. Adjustment for multiple comparisons: Least Significant Difference (equivalent to no adjustments).

*. The mean difference is significant at the, 050 level.

Analisis data juga menghasilkan interaksi pada masing-masing time (pre-post1post2) pada kelompok kontrol dan kelompok eksperimen. Hasil analisis data ini menunjukkan bahwa perubahan penguasaan penyusunan program pembelajaran pendidikan karakter anak usia dini pada kelompok eksperimen setelah diberikan perlakuan adalah signifikan ( $M D=-6,824 ; \mathrm{p}<0,00$ ), nilai MD negatif menunjukkan bahwa rerata post-tes1 lebih tinggi dibanding rerata pre-tes artinya penguasaan subjek mengalami peningkatan. Sementara pada kelompok kontrol sebelum diberikan perlakuan adalah tidak signifikan ( $\mathrm{MD}=-0,353 ; \mathrm{p}>0,05$ ). Setelah mendapatkan perlakuan diperoleh hasil ada perubahan penguasaan penyusunan program pembelajaran pendidikan karakter anak usia dini secara signifikan pada kelompok kontrol $(\mathrm{MD}=-5,412 ; \mathrm{p}<0,00)$. Nilai MD negatif menunjukkan bahwa ada peningkatan penguasaan pada diri subjek. 
Tabel 3. Multivariat Test

\begin{tabular}{|c|c|c|c|c|c|c|c|}
\hline Group & & Value & $\mathrm{F}$ & $\begin{array}{c}\text { Hypothesis } \\
\text { df }\end{array}$ & Error df & Sig. & $\begin{array}{c}\text { Partial Eta } \\
\text { Squared }\end{array}$ \\
\hline \multirow[t]{4}{*}{2} & $\begin{array}{l}\text { Pillai's } \\
\text { trace }\end{array}$ & .617 & 24.932 & 2.000 & 31.000 & .000 & .617 \\
\hline & $\begin{array}{l}\text { Wilks' } \\
\text { lambda }\end{array}$ & .383 & 24.932 & 2.000 & 31.000 & .000 & .617 \\
\hline & $\begin{array}{l}\text { Hotelling's } \\
\text { trace }\end{array}$ & 1.609 & 24.932 & 2.000 & 31.000 & .000 & .617 \\
\hline & $\begin{array}{l}\text { Roy's } \\
\text { largest } \\
\text { root }\end{array}$ & 1.609 & 24.932 & 2.000 & 31.000 & .000 & .617 \\
\hline
\end{tabular}

Hasil partial eta square pada kelompok eksperimen diketahui sebesar 0,617. Hal ini menunjukkan bahwa sumbangan efektif pelatihan pada kelompok eksperimen sebesar $61,7 \%$.

Dari hasil analisis data diatas, tujuan penelitian yang dimaksudkan untuk menguji pelatihan My Plan My Success dalam meningkatkan penguasaan guru TK dalam menyusun program pembelajaran pendidikan karakter AUD tercapai. Pelatihan My Plan My Success mampu meningkatkan penguasaan guru TK dalam menyusun program pembelajaran pendidikan karakter AUD sebesar 61,7\%. Hal ini memberikan makna bahwa Pelatihan My Plan My Success dapat digunakan sebagai salah satu pilihan kegiatan yang dapat diberikan pada guru TK untuk memaksimalkan penerapan pembelajaran pendidikan karakter di taman kanak-kanak.

Hasil yang diperoleh dari penelitian ini sejalan dengan penelitian-penelitian yang telah ada bahwa penggunaan metode pelatihan terbukti efektif untuk meningkatkan pemahaman, penguasaan dan ketrampilan guru pada suatu materi pembelajaran (When Chong, 2010; Wati, 2012; Pistorio, 2009; Sariçoban \& Bariskan, 2005). Metode pelatihan menjadi efektif karena di dalamnya mencakup suatu pembelajaran atas pengalaman-pengalaman, pelatihan menjadi suatu kegiatan keorganisasian yang direncanakan dan dirancang didalam menanggapi kebutuhan-kebutuhan yang teridentifikasi pada peserta pelatihan (Bernardin \& Russel, 1998). Pendekatan experiential learning yang digunakan dalam pelatihan My Plan My Success dalam penelitian ini telah mengaktifkan peserta pelatihan sebagai subjek penelitian yang dalam hal ini berposisi sebagai pembelajar untuk membangun pengetahuan dan ketrampilan serta nilai-nilai juga sikap melalui pengalamannya secara langsung. 
Experiential learning menggunakan pengalaman sebagai katalisator untuk menolong pembelajar mengembangkan kapasitas dan kemampuannya dalam proses pembelajaran (Kolb, Boyatzis \& Maeremelis, 1999). Materi-materi dalam pelatihan My Plan Plan My Success dalam penelitian ini disajikan melalui proses role game, diskusi kelompok dan studi kasus yang memungkinkan peserta pelatihan mendapatkan pengalaman-pengalaman langsung, menyampaikan secara lisan dan menuangkan dalam bentuk tulisan.

Prosedur pembelajaran dalam experiential learning menurut Kolb (1984) terdiri dari 4 tahapan, yaitu; 1) tahapan pengalaman nyata, 2) tahap observasi refleksi, 3) tahap konseptualisasi, dan 4) tahap implementasi. Proses belajar subjek penelitian sebagai peserta pelatihan dimulai dari pengalaman konkret dalam bentuk role game, diskusi kasus atau penugasan. Pengalaman tersebut kemudian direfleksikan secara individu dipandu oleh trainer dengan pancingan pertanyaan. Dalam proses refleksi peserta pelatihan akan berusaha memahami apa yang terjadi atau apa yang dialaminya. Pengalaman yang telah direfleksikan kemudian diatur kembali sehingga membentuk pengertian-pengertian baru atau konsep-konsep abstrak yang akan menjadi petunjuk bagi terciptanya pengalaman atau perilaku-perilaku baru. Refleksi ini bagi peserta pelatihan menjadi dasar konseptualisasi atau proses pemahaman prinsip-prinsip yang mendasari pengalaman yang dialami serta prakiraan kemungkinan aplikasinya dalam situasi atau konteks yang lain (baru). Setelah peserta pelatihan mendapatkan pengertian-pengertian baru kemudian mereka menjalani proses implementasi yaitu penerapan konsep dan pengertian-pengetian baru yang sudah dikuasai dengan menyusun program pembelajaran pendidikan karakter AUD langkah demi langkah. Proses pengalaman dan refleksi dikategorikan sebagai proses penemuan (finding out), sedangkan proses konseptualisasi dan implementasi dikategorikan dalam proses penerapan (taking action). Menurut Johnson (2012) teori belajar humanistik didasarkan pada premis bahwa semua manusia memiliki kecenderungan alami untuk tumbuh, belajar, dan berkembang sepenuhnya. Carl Rogers menggambarkan hal ini sebagai naluri utama yang menggerakkan manusia untuk mencapai potensi mereka secara penuh. Abraham Maslow menggunakan istilah "aktualisasi diri” untuk menggambarkan naluri bawaan manusia yang bergerak maju secara natural untuk mencapai kondisi tertinggi. Praktek menyusun program pembelajaran pendidikan karakter yang dilakukan oleh peserta pelatihan setelah mereka mendapatkan pengertian-pengertian baru pada setiap akhir sessi dan pada setiap langkah model Kemp adalah bentuk aktualisasi diri peserta karena mereka berusaha mengungkapkan dan menuangkan potensi mereka secara nyata. 
Menurut Rogers (dalam Baharudin \& Makin, 2007) dalam teori belajar humanistik proses pembelajaran harus memperhatikan prinsip-prinsip dasar humanistik antara lain manusia mempunyai kemampuan belajar secara alami, belajar yang bermakna diperoleh pembelajar dengan melakukannya, belajar diperlancar bilamana pembelajar dilibatkan dan ikut bertanggung jawab dalam proses belajar, proses belajar mendorong pembelajar untuk memiliki inisiatif sendiri yang melibatkan pribadi pembelajar seutuhnya. Peserta pelatihan dalam penelitian ini dilibatkan secara penuh selama proses pelatihan berlangsung, peserta pelatihan difasilitasi untuk berbicara mengungkapkan pendapatnya, bertanya sewaktu-waktu dan menceritakan pengalaman yang dimiliki. Trainer sebatas bertindak sebagai fasilitator yang mengajak peserta untuk mengeskplor pendapat dan pemikirannya sendiri serta berusaha secara mandiri untuk menemukan pengetahuan-pengetahuan yang hendak disampaikan dalam materi pelatihan.

Materi pelatihan yang diberikan kepada peserta pelatihan sebagai subjek penelitian adalah bagaimana cara penyusunan program pembelajaran pendidikan karakter anak usia dini. Materi ini disampaikan menggunakan langkah-langkah pendekatan instructional design Model Kemp. Model ini mengetengahkan delapan langkah dalam menyusun program pembelajaran yang mudah dipahami, sistematis dan memungkinkan terjadinya interaksi yang maksimal antara trainer sebagai pemateri dan peserta sebagai pembelajar aktif. Hal ini bisa terjadi karena menurut Kowch (2004) model Kemp disusun berdasarkan teori-teori belajar, mempertimbangkan perkembangan teknologi informasi, analisis yang sistematis dan metode manajemen belajar, yang sesuai dengan perkembangan zaman dan memperhatikan kebutuhan guru sebagai aktor yang berperan dalam penyusunan program pembelajaran. Subjek penelitian yang dalam hal ini adalah para guru TK memungkinkan mampu menyerap materi yang disampaikan dengan lebih mudah karena sesuai dengan kebutuhannya didukung dengan interaksi aktif antara trainer dengan peserta selama proses pelatihan berlangsung. Sehingga peningkatan penguasaan guru terhadap penyusunan program pembelajaran pendidikan karakter AUD setelah mengikuti pelatihan dapat tercapai. Hal ini juga bisa terjadi karena latar belakang pendidikan subjek penelitian adalah guru TK yang memiliki kualifikasi pendidikan sarjana. Seseorang dengan latar belakang pendidikan sarjana memiliki pola pikir yang lebih sistematis sehingga lebih mudah dalam menerima materi baru.

Berdasarkan hasil penelitian yang telah didapatkan, ada beberapa saran yang bisa diberikan, yaitu :

1. Diperlukan penelitian lanjutan untuk melihat efektivitas pelatihan My Plan My 
Success dan dampaknya terhadap penerapan program pembelajaran pendidikan karakter di taman kanak-kanak.

2. Modul pelatihan My Plan My Success perlu diujicobakan pada guru TK dengan latar belakang pendidikan dibawah sarjana sehingga penggunaannya bisa lebih luas dan maksimal.

\section{Simpulan}

Berdasar pada paparan hasil penelitian dan diskusi tersebut diatas dapat ditarik kesimpulan bahwa ada peningkatan penguasaan penyusunan program pembelajaran pendidikan karakter pada peserta (kelompok eksperimen) yang mendapatkan perlakuan pelatihan My Plan My Success dibandingkan dengan pesrta (kelompok kontrol) yang tidak mendapatkan perlakuan. Hal ini menunjukkan bahwa pelatihan My Plan My Success dapat digunakan untuk meningkatkan penguasaan guru TK dalam melakukan penyusunan program pembelajaran pendidikan karakter anak usia dini. Metode pelatihan My Plan My Success memfasilitasi dan melibatkan peserta secara penuh untuk belajar dari pengalaman yang diciptakan selama proses pelatihan berlangsung. Pengalaman ini berfungsi sebagai katalisator yang menolong peserta pelatihan untuk mengembangkan kapasitas dan kemampuannya.

\section{Daftar Pustaka}

Akbulut, Y., (2007). Implications of two well-known models for instructional designers in distance education: Dick-Carey Versus Morrison-Ross-Kemp. Turkish Online Journal of Distance Education-TOJDE, 8(2). ISSN 1302-6488

Antara News (2012). Wamendikbud: Pendidikan karakter terkendala pemahaman guru.Artikel.Diunduh dari http://www.antaranews.com

Baharuddin, Makin (2007).Pendidikan humanistik: Konsep, Teori dan aplikasi praktis dalam dunia pendidikan. Yogyakarta: Ar-Ruz Media.

Berkowitz, M.W., Bier, M.C. (2004). Research-based character education. Annals of the American Academy of Political and Social Science, 591, 7285.

Berkowitz, M.W., Hoppe, M.A. (2009). Character education and gifted children.High Ability Studies, 20(2), ISSN 1359-8139 print/ISSN 1469834X.doi: 10.1080/13598130903358493

Berkowitz, M.W., Schwartz. (2006). Children Needs III, Chapter 2 : Character 
Education. Development, prevention, and intervention.Bethesda, MD: National Association of School Psychologist.

Bernardin, H.J., Russell, J.E.A.,(1998).Human resource management, second edition. Singapore: McGraw-Hill Book Co

Handoyo, B. (2012). Kendala-kendala implementasi pendidikan karakter di sekolah.Karya Ilmiah. Malang: Universitas Negeri Malang.

Howard, R.W., Berkowitz, M.W., Schaeffer, E.F. (2004). Politics of character education.Educational Policy. 18(1), 188-215. doi: 10.1177/ 0895904803260031

Irastorza, C.S., Begin, S., Fabry, D.L. (2008). Developing a systematic approach to program review.Journal Of Research In Innovative Teaching. 1(1)

Kementrian Pendidikan Nasional. (2011). Pedoman pendidikan karakter bagi $A U D$. Direktorat jenderal pendidikan anak usia dini, nonformal dan informal. direktorat pendidikan AUD.

Kementerian Pendidikan Nasional, (2011).Badan penelitian dan pengembanganpusat kurikulum dan perbukuan.

Kolb, D. (1984). Experiential learning: experience as the source of learning and development.Englewood Cliffs, NJ: Prentice Hall.

Kolb, D., Boyatzis, R.E, Mairemelis, C. (1999).Experiential Learning Theory:

Previous Research and New Directions.Department of Organizational Behavior Weatherhead School of Management Case Western Reserve University.

Kowch, E. (2004). Review Essay: Designing effective instruction (4th Ed.) by Gary R. Morrison, Steven M. Ross, and Jerrold E. Kemp.University of Calgary.

Lickona, T. (1992).Educating for Character: How Our Schools Can Teach Respect and Responsibility.New York: Bantam Books.

Milkova, (2011).Strategies for Effective Lesson Planning.The Regents of the University of Michigan.

Morrison, G.R., Ross, S.M., and Kemp, J.E. (2004).Designing effective instruction. $4^{\text {th }}$ Edition. Hoboken, NJ: John Wiley \& Sons, Inc.

Muliartha, (2011).Model desain pembelajaran. Teknologi Pembelajaran. Undiksha. 
Noe, R.A., Hollenbeck, J.R., Gerhart, B., Wright, P.M. (2003). Human resources management : gaining a competitive advantage. $4^{\text {th }}$ Edition. New York: The McGraw-Hill Companies, Inc.

Nugraha, M.S., (2009). Mutu guru di indonesia masih terbilang rendah, pemerintah harus fokus pada peningkatan kompetensinya. Pikiran Rakyat: Bandung.

Nurchaili, (2011).Keteladanan Guru dan Pendidikan Karakter. Opini.

Park, E., Confessore, G.J., (2007). An interactive model of instructional development.International Journal Of Self-Directed Learning. 4(2).

Pedoman Pendidikan Karakter Pada Pendidikan Anak Usia Dini (2012). Direktorat pembinaan pendidikan anak usia dini. Direktorat Jenderal Pendidikan Anak Usia Dini, Nonformal, dan Informal. Jakarta: Kementerian Pendidikan Nasional.

Peters, R.S. (2009). Moral education and the psychology of character1.Journal of Philosophy. 37(139), 37-56 doi: 10.1017/S0031819100030850

Pfeiffer, J.W., \& Ballew, A.C. (1988).Using structured experiences in human resource development, 1.

Pistorio, María Inés. (2009). Teacher Training and Competences for Effective CLIL Teaching in Argentina.Latin American Journal of Content \& Language Integrated Learning. 2(2).37-43.

Rivers, T.M. (2004). Ten essentials for character education. The Journal Of General Education, 53(3-4), 247-260.

Rogers, C. (1987). Carl Roger: On person-centered therapy.

Saddington, T. (1990). The roots and branches of Experiential Learning.Paper.Centre for Extra-Mural Studies, University of Cape Town,

Saptono, (2012).Pendidikan berkarakter harus diterapkan secara serius. Medan: MedanMagazine.

Sariçoban, A., Bariskan, V. (2005). The effectiveness of pre-service teacher training inclassroom management skills, Journal of Language and Linguistic Studies, 1(2).

Schaeffer, E.F (1999). It's time for schools to implement character education. National Association of Secondary School Principals. NASSP Bulletin, 83(609) 
Schultz, L.H., Selman, R.L., Larusso, A.D. (2003). The assessment of psychosocial maturity in children and adolescents implications for the evaluation of schoolbased character education programs.Journal Of Research In Character, 1(2). ISSN: $1543-1223$

Singer, M.J. (2010). Character education, Dr Seuss and Te Whariki:A likely combination. Australasian Journal of Early Childhood, 35(2).

Supriyoko, K. (2002). Pendidikan Karakter Butuh Keteladanan.Artikel.Jakarta: Kompas.

Wati, H. (2011). The effectiveness of indonesian english teachers training programs in improving confidence andmotivation, International Journal of Instruction, 4(1). ISSN: 1308-1470

Wen Chong, P. (2010). Comparative Analysis of Special Education Teacher Training in France and Norway: How effective, areas taught and recommendation for improvement (Master Thesis Abstract), Journal for Educators, Teachers and Trainers JETT, Vol. 1, pp. 87-95.

Widhiarso, W. (2011).Anava desain campuran.Artikel. Yogyakarta: Fakultas Psikologi UGM. 